\title{
Obituary for Carole Beal
}

\section{Beverly Woolf ${ }^{1}$}

Published online: 26 January 2022

(c) International Artificial Intelligence in Education Society 2021, corrected publication 2020

We are saddened to announce the passing of our dear colleague Carole Ruth Beal on July 28, 2021 at her home in Pittsburgh, from an atypical form of Parkinson's Disease. These brief remembrances tell about Carole's brilliance, grace and generosity, and her many accomplishments. In Memoriam, a site about Carole, was developed by her husband. Many wonderful research and personal relationships have ended with her death (https://sites.google.com/view/caroleruthbeal/home). We will miss her greatly.

Carole was at the forefront of educational technology and one of the rare technologists who had the skills to not only build systems but field and test them as a psychologist, in proper experiments. She was a professor in the University of Florida's School of Teaching and Learning and was previously a professor of science, technology and the arts at the University of Arizona's School of Information. Carole developed the landmark Animal Watch system for teaching pre-algebra first at the University of

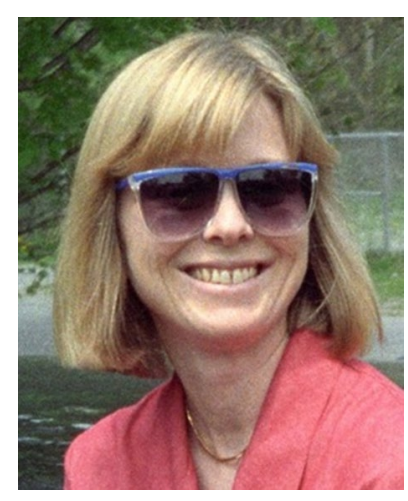

Beverly Woolf

bev@cs.umass.edu

1 University of Massachusetts, Amherst, MA 01003, USA 


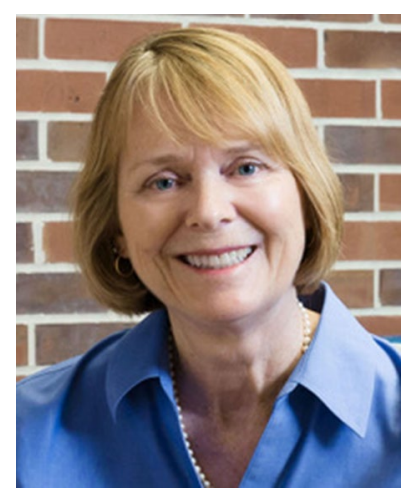

Massachusetts and then at the USC Information Sciences Institute. AnimalWatch was an intelligent tutoring system that focused uniquely on word problem solving, a core component of mathematics proficiency. At the University of Arizona, she extended her work to teach mathematics to visually impaired students, supporting them to build pre-algebra skills and to interpret graphic information (e.g., bar graphs, maps). She explored the potential of precision education to improve achievement for all students through strategies to personalize online learning. A Pre-Eminent Professor in the School of Education at the University of Florida, she won over \$10M in grants from the U.S. Department of Education Institute of Education Sciences.

Carole leaves her husband of 50 years, Paul Cohen, professor of Computer Science at the University of Pittsburgh, and her daughter Allegra Beal Cohen, Postdoctoral Researcher at University of Florida.

Publisher's Note Springer Nature remains neutral with regard to jurisdictional claims in published maps and institutional affiliations. 